\title{
Cutaneous metastasis from colon cancer: an unusual and late presentation form to considerate
}

\author{
Metástasis cutánea de cáncer de colon: una forma de presentación inusual y tardía a \\ tener en cuenta \\ Jeancarlos J. Trujillo-Díaz*, María Ruiz-Soriano, Mario A. Montes-Manrique, José C. López-López, \\ Andrea Vázquez-Fernández and Juan P. Beltrán de Heredia y Rentería \\ Department of General and Digestive System Surgery, Hospital Clínico Universitario, Valladolid, Spain
}

\begin{abstract}
Introduction: Colorectal cancer is a big health problem due to its high incidence and mortality. Cutaneous metastases are rare with an incidence $<5 \%$. Clinical case: $A$ male with a history of colectomy due to colon cancer, who 6 years later presented a cutaneous lesion. The biopsy reported colonic metastasis, so radical surgical resection was performed. The pathological anatomy confirmed a moderately differentiated adenocarcinoma compatible with colonic metastasis. Discussion and conclusion: Cutaneous metastases are rare and when they appear they indicate an advanced disease, for that reason is important a high index of suspicion in patients at risk, for an early diagnosis.
\end{abstract}

KEY WORDS: Colorectal cancer. Metastasis. Cutaneous metastasis.

\section{Resumen}

Introducción: El cáncer colorrectal es un gran problema de salud por su alta incidencia y mortalidad. Las metástasis cutáneas son raras, con una incidencia < 5\%. Caso clínico: Varón con antecedente de colectomía por neoplasia de colon que 6 años después presenta una lesión cutánea. La biopsia informa de metástasis colónica, por lo que se realiza resección quirúrgica radical. La anatomía patológica confirma un adenocarcinoma moderadamente diferenciado compatible con metástasis colónica. Discusión y conclusiones: Las metástasis cutáneas son raras y cuando aparecen nos indican una enfermedad avanzada, por lo que es importante un alto índice de sospecha en pacientes de riesgo para un diagnóstico precoz.

PALABRAS CLAVE: Cáncer colorrectal. Metástasis. Metástasis cutánea.

\section{Correspondence:}

*Jeancarlos J. Trujillo-Díaz

Av. Ramón y Cajal, 3

47003 Valladolid, España

E-mail: jeancar5671@gmail.com
Date of reception: 21-02-2018

Date of acceptance: $21-04-2018$

DOI: $10.24875 / C I R U E . M 18000042$
Cir Cir. 2018;86:254-257

Contents available at PubMed www.cirugiaycirujanos.com 


\section{Introduction}

Colorectal cancer is a major health problem owing both to its high incidence and to its mortality. According to data from the World Health Organization, colorectal cancer is the third most common tumor in men ( $10 \%$ of total worldwide cancer) and the second most common in women (9.2\% of total cancer worldwide). In Spain, colorectal cancer is currently the most common malignancy.

Colorectal cancer is spread by the lymphatic, peritoneal and hematogenous routes and by contiguity. The most frequently affected organ by hematogenous dissemination is the liver, and it is estimated that approximately half the patients with colorectal cancer will develop liver metastases sometime during the course of the disease'.

On the other hand, cutaneous metastases from colorectal cancer are rare, with an incidence lower than $5 \%$. In general, skin metastases occur in between $0.7 \%$ and $5 \%$ of patients with some visceral neoplasm, and can occur in up to $10 \%$ in patients with metastatic cancer ${ }^{2}$.

We discuss the case of a male patient with colon neoplasm with a single skin lesion in the abdominal wall.

\section{Clinical case}

Eighty-six-year-old male patient with a medical history of hypertension, chronic ischemic heart disease, and a surgical history of left nephrectomy due to a renal tumor (1998), left hip prosthesis, subtotal colectomy due to sigmoid colon neoplasm, and adenomatous polyposis (2012), hepatic metastasectomy for a synchronous lesion in segment VIII (2012) and peritonitis due to intestinal perforation (2013). He attended a control visit and referred the presence of a skin lesion in the abdomen, 6 years after the first colon neoplasm surgery. On examination, a nodular, ovalshaped, raised, hyperpigmented $3 \times 2-\mathrm{cm}$ skin lesion that was soft on palpation and non-painful, was observed on the abdominal wall at the left flank (Fig. 1). Blood tests with tumor markers showed no noticeable alterations. In the last control tomography, no new lesions consistent with relapse were observed.

Initially, a biopsy of the lesion reported the presence of moderately differentiated adenocarcinoma, consistent with metastasis of colonic origin. Given this finding, radical surgical excision of the lesion was performed. Pathological anatomy examination of the

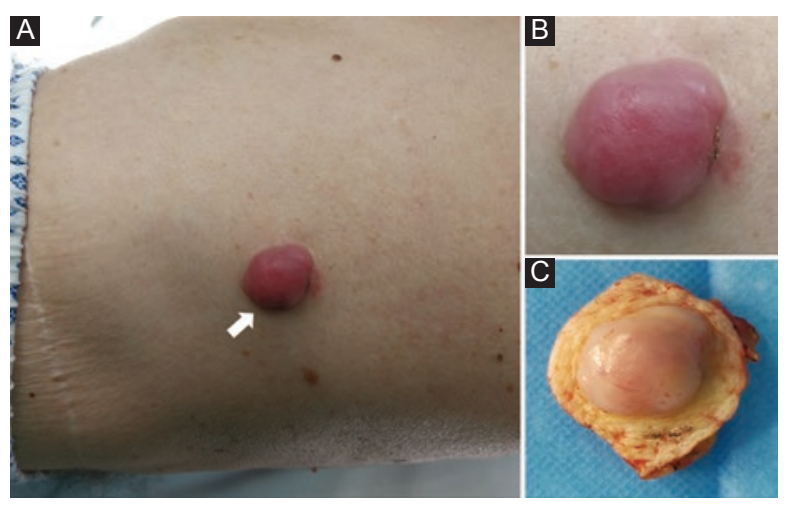

Figure 1. A: panoramic view of the skin lesion located in the abdominal wall left lateral region (arrow). B: raised, hyperpigmented $3 \times 2-\mathrm{cm}$ nodular skin lesion. C: surgical specimen after radical excision, with margins free of neoplastic infiltration.

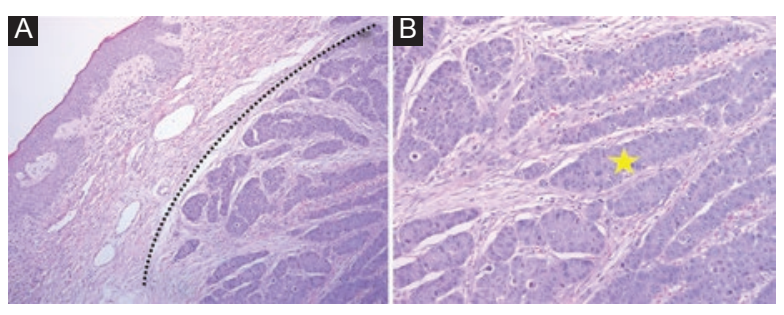

Figure 2. Histological findings. A: vision at 10x: epidermis and superficial dermis, free of neoplastic infiltration (above the dotted line). B: vision at 20x: reticular dermis intense tumor infiltration. Moderately differentiated adenocarcinoma (star).

surgical specimen confirmed it was a moderately differentiated adenocarcinoma, consistent with metastasis of colonic origin. The tumor completely occupied the dermis and reached the superficial subcutaneous cellular tissue; the lateral and deep surgical margins were free of neoplastic infiltration (Fig. 2).

\section{Discussion}

Cutaneous metastases from colorectal cancer account for $2 \%$ of all skin tumors, and often appear together with metastases to other organs. The cancers that most frequently metastasize to the skin are melanoma, breast cancer and upper respiratory tract cancer, with colorectal cancer being a very rare source of cutaneous metastases ${ }^{1}$. The finding of cutaneous metastases at primary tumor presentation occurs in approximately $1.3 \%$ of cases $^{3}$. Cutaneous metastases occur in approximately $5 \%$ of colorectal cancers ${ }^{4}$.

The most frequent sites of colorectal cancer cutaneous metastases are the abdomen (usually in areas close to the primary tumor and are due to direct extension or local implantation during surgery in the area of surgical incision), the limbs, the perineum, the head, neck and penis, either by lymphatic or 
hematogenous dissemination, or by direct implantation during surgery ${ }^{3,4}$.

In a study conducted by Hu et al. ${ }^{5}$, primary tumor sources of metastases were reported to be the following: rectum $55 \%$, sigmoid colon $17 \%$, transverse colon $9 \%$, rectosigmoid colon $7 \%$, cecum $4 \%$ and ascending colon $4 \%{ }^{5}$.

Cutaneous metastases from colorectal cancer usually occur within the first 2 years after resection of the primary colorectal tumor, and often do it simultaneously with metastases to the liver, peritoneum, and lung ${ }^{3,6}$.

Metastases occur when neoplastic cells detach from a primary tumor and spread to other places. The mechanism for the production of cutaneous metastases is variable and several routes have been implicated in their development. The hematogenous and lymphatic routes are the most common, although differentiation between both is difficult because they are interconnected. Lymphatic dissemination is the most common route for initial spread of most malignant tumors. Direct implantation of tumor cells can be produced by tumor fragments mechanical transport by surgical instruments during surgery or other invasive procedures, but this rarely occurs?

Cutaneous metastases clinical presentations are varied and nonspecific, with the most common form being dermal or subcutaneous nodules of $1-2 \mathrm{~cm}$ in diameter that are painless, indurated, mobile, single or multiple, with no changes in the overlying epidermis. Occasionally they may show rapid growth, bullae or fibrotic processes, or ulcerate and cause cellulitis ${ }^{1,3}$.

Given the rarity of these lesions, and since they do not have a uniform appearance at presentation, it is not uncommon for them to initially be misdiagnosed as simple cysts or benign connective tissue lesions, pyogenic granulomas, granular cell tumors, benign cysts, neurofibromas or lipomas. Therefore, in the presence of atypical or persistent nodular lesions in patients with a history of malignant neoplasms, a biopsy should be considered in order to rule out the possibility of metastasis ${ }^{2,4}$.

Thus, if cutaneous involvement of a malignancy is suspected, there are two ways to obtain tissue for diagnostic confirmation: by biopsy or fine-needle aspiration, with the latter perhaps being faster and more efficient ${ }^{1}$. The diagnosis is based on morphological and histological aspects and on immunohistochemistry examination of the cutaneous lesion, together with a comparison with the morphology and histology of the primary tumor ${ }^{3}$. Morphohistological characteristics of metastatic lesions in general resemble those of the primary tumor. However, metastases are often more anaplastic.

In general, cutaneous metastases can be classified as adenocarcinoma, squamous cell carcinoma, undifferentiated carcinoma and other types. Most skin metastases from colorectal tumors are well differentiated, and they are often mucin-secreting adenocarcinomas. They usually have a nodular configuration and are located in the dermis, with subsequent dissemination to the epidermis and subcutaneous tissue ${ }^{2}$. When tumors are poorly differentiated or anaplastic, immunohistochemical detection tests, such as CK7, CK20, CK19, CDX2, CEA and mucin, are highly useful ${ }^{4,6}$.

The treatment of cutaneous metastases from colorectal cancer is limited and there is no standardized therapeutic strategy. Although the treatment of metastatic colorectal cancer has been based on systemic chemotherapy, surgical resection in selected patients with cutaneous metastases offers the only possibility of long-term survival ${ }^{3}$. For isolated lesions, Nesseris et al. ${ }^{2}$ suggested wide local excision with subsequent reconstruction. However, Wong et al. ${ }^{8}$ proposed the typical resection with a $1-\mathrm{cm}$ margin of healthy skin, and in some areas of high esthetic importance or when the treatment is palliative, excision with much more limited margins can be performed.

For patients with multiple cutaneous metastases or unresectable lesions, systemic chemotherapy may be considered. However, there is no optimal chemotherapy regimen. Established chemotherapy treatments include 5-fluorouracil (5-FU), capecitabine, irinotecan, oxaliplatin and cisplatin. Combinations of irinotecan and 5-FU, oxaliplatin and 5-FU and leucovorin (LV) (FOLFOX), or 5-FU/LV with irinotecan (FOLFIRI), have increased survival to over 20 months. Sequential treatment of patients with FOLFIRI followed by FOLFOX, or with FOLFOX followed by FOLFIRI, has increased median survival times to 21.5 months and 20.6 months, respectively ${ }^{2}$. Radiotherapy, polychemotherapy, isolated infusion of extremities, interferon alfa injections, cryotherapy, laser ablation, radiofrequency ablation, $5 \%$ imiquimod cream and oncogene-targeted therapy are treatments that are also used, but without scientific evidence demonstrating their efficacy ${ }^{3}$.

Therefore, the finding of a cutaneous metastasis is indicative of an advanced stage of colorectal cancer, with life expectancy after cutaneous metastases diagnosis ranging from 1 to 34 months. Therefore, the treatment will generally be palliative and aimed at 
improving patient quality of life $^{2}$. The most important is early detection and treatment of colorectal cancer in order to prevent or reduce the occurrence of disseminated skin metastases and thus increase life expectancy of these patients ${ }^{6}$.

\section{Conclusions}

In conclusion, cutaneous metastases from colorectal cancer have a low incidence, but when they occur, they usually indicate an advanced disease and, therefore, a poor prognosis. The key point is early diagnosis, which requires a careful physical examination and a high index of suspicion in at-risk patients, since these injuries can go unnoticed for prolonged periods. If cutaneous metastasis are suspected, it is essential for a biopsy to be obtained in order to confirm the diagnosis, and thus stage the disease and consider the best therapeutic management, which can be medical or surgical.

\section{Conflicts of interest}

There are no conflicts of interest involving any of the authors.

\section{References}

1. De Miguel M, Fraile M, Yagüe A, Oteiza F, Ciga M, Armendáriz $P$, et al. Metástasis cutáneas de cáncer de recto. An Sist Sanit Navar. 2013; 36:557-61.

2. Nesseris I, Tsamakis C, Gregoriou S, Ditsos I, Christofidou E, Rigopoulos D. Cutaneous metastasis of colon adenocarcinoma: case report and review of the literature. An Bras Dermatol. 2013;88:56-8.

3. Wang DY, Ye F, Lin JJ, Xu X. Cutaneous metastasis: a rare phenomenon of colorectal cancer. Ann Surg Treat Res. 2017;93:277-80.

4. Fragulidis GP, Vezakis A, Derpapas MK, Michalaki V, Tsagkas A, Polydorou AA. Cutaneous metastatic adenocarcinoma of the colon to the scalp. World J Oncol. 2015;6:304-7.

5. Hu S, Chen G, Lu Y, Wu C, Lan C. Cutaneous metastases from different internal malignancies: a clinical and prognostic appraisal. J Eur Acad Dermatol Venereol. 2008;22:735-40.

6. Hashimi Y, Dholakia S. Facial cutaneous metastasis of colorectal adenocarcinoma. BMJ Case Rep. 2013;2013:bcr2013009875.

7. Fernández-Antón M, Parra-Blanco V, Avilés J, Suárez R. Metástasis cutáneas de origen visceral. Actas Dermosifiliogr. 2013;104:841-53.

8. Wong CY, Helm MA, Kalb RE, Helm TN, Zeitouni NC. The presentation, pathology, and current management strategies of cutaneous metastasis. N Am J Med Sci. 2013;5:499-504. 